\title{
Correction to: Dependence of Tribological Performance and Tribopolymerization on the Surface Binding Strength of Selected Cycloalkane-Carboxylic Acid Additives
}

\author{
Qiang Ma ${ }^{1,3} \cdot$ Arman Mohammad Khan ${ }^{1} \cdot$ Q. Jane Wang ${ }^{1} \cdot$ Yip-Wah-Chung ${ }^{1,2}$
}

Published online: 10 September 2020

(c) Springer Science+Business Media, LLC, part of Springer Nature 2020

\section{Correction to: Tribology Letters (2020) 68:86 \\ https://doi.org/10.1007/s11249-020-01329-2}

The original publication contained an incorrect mention of the time duration for Fig. 12 in Appendix. The expanded friction curve is for the initial $30 \mathrm{~s}$ of sliding.

Publisher's Note Springer Nature remains neutral with regard to jurisdictional claims in published maps and institutional affiliations.

The original article can be found online at https://doi.org/10.1007/ s11249-020-01329-2.

Q. Jane Wang

qwang@northwestern.edu

$\triangle$ Yip-Wah-Chung

ywchung@ northwestern.edu

1 Department of Mechanical Engineering, Northwestern University, Evanston, IL 60208, USA

2 Department of Materials Science and Engineering, Northwestern University, Evanston, IL 60208, USA

3 Key Laboratory of Education Ministry for Modern Design and Rotor Bearing Systems, Xi' an Jiaotong University, Xi'an 710049, People's Republic of China 